\title{
Photochemical origin of the darkening of copper acetate and resinate pigments in historical paintings.
}

Marion Alter ${ }^{\dagger}$, Laurent Binet ${ }^{\dagger}$, Nadia Touati ${ }^{\ddagger}$, Nadège Lubin-Germain\&, Anne-Solenn Le Hô ${ }^{\ddagger \dagger}$, François Mirambet ${ }^{\dagger}$, Didier Gourier* ${ }^{\dagger}$

${ }^{\dagger}$ Chimie-ParisTech, PSL University, CNRS, Institut de Recherche de Chimie de Paris (IRCP), Paris, France.

$\$$ Centre de Recherche et de Restauration des Musées de France (C2RMF), Palais du Louvre, Paris, France.

\& Laboratoire de Chimie Biologique (LCB), EA4505, Université de Cergy-Pontoise, Cergy-Pontoise, France

Corresponding author

*Didier Gourier didier.gourier@chimieparistech.psl.eu

\section{Supporting Information}

1. Spin level energy diagram for a bimetallic $\mathrm{Cu}^{\mathrm{II}}$ complex.

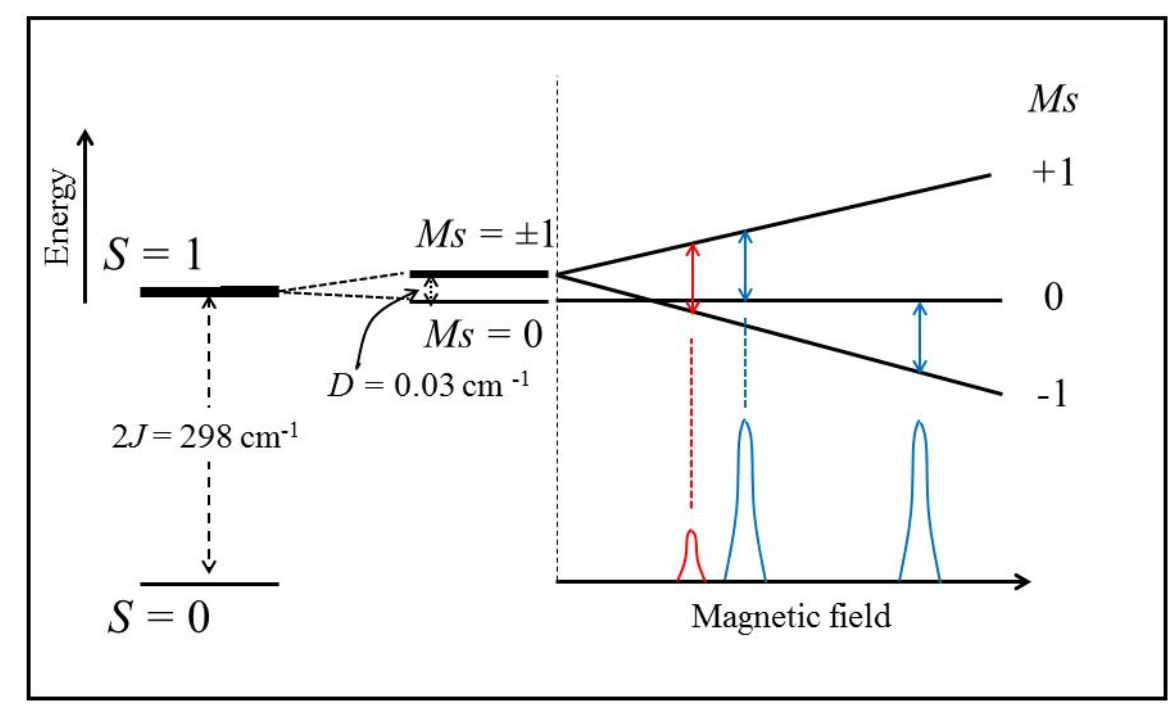

Figure S1: Schematic diagram of spin level energy for a bimetallic $\mathrm{Cu}^{\mathrm{II}}$ complex with axial symmetry and with magnetic field $\mathrm{B}_{0}$ oriented parallel to the $\mathrm{Cu}^{\mathrm{II}}-\mathrm{Cu}^{\mathrm{II}}$ direction. EPR transitions $\Delta M s=1$ (blue) and $\Delta M s=2(\mathrm{red})$ illustrate the situation at Q-band (see Fig.3A). 
2. EPR and OAS spectra of copper acetate in raw linseed oil.
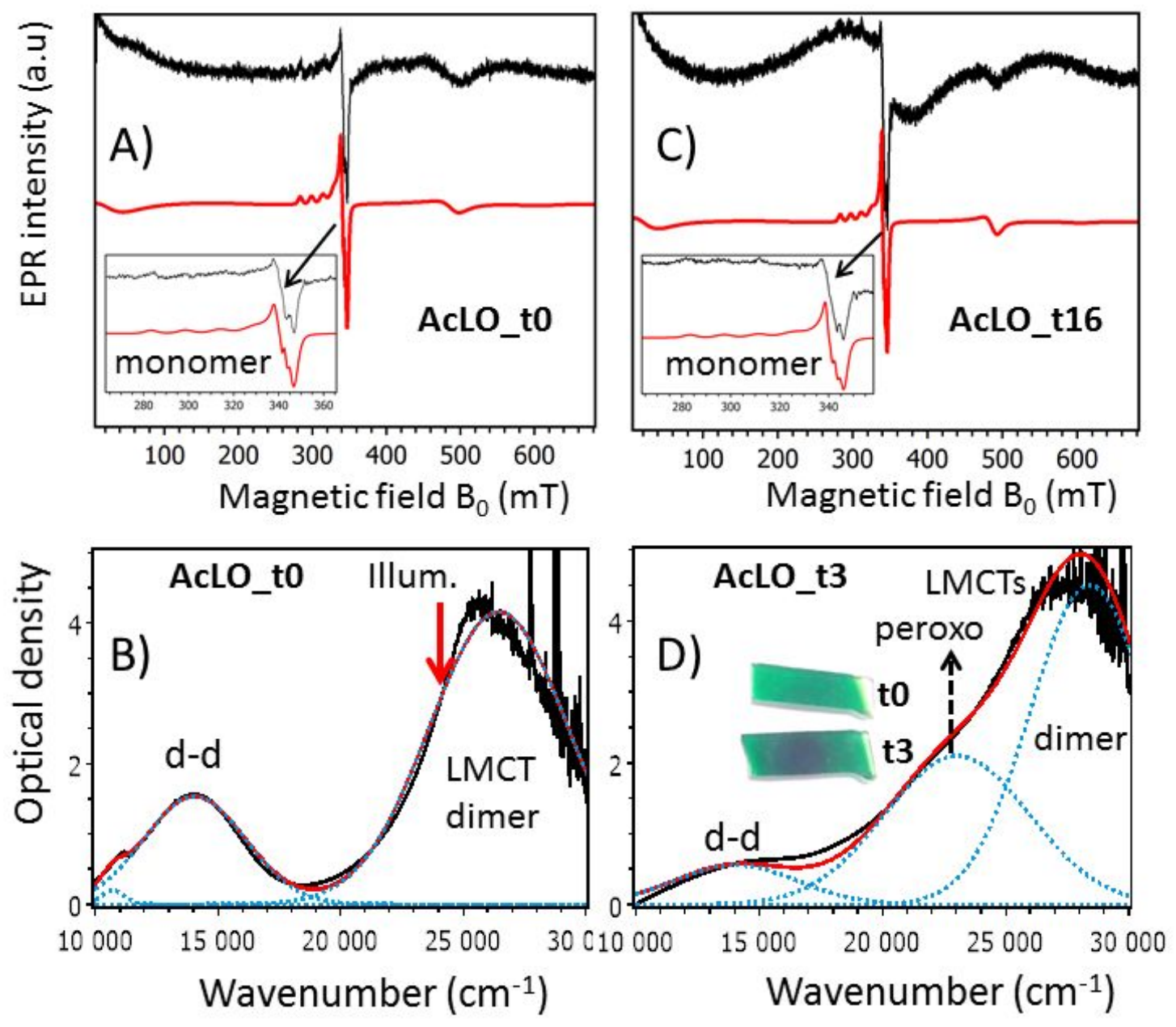

Figure S2. Experimental (black lines) and simulated (red lines) X-band EPR and OAS spectra of copper acetate / linseed oil film before LED illumination (AcLO_to) and after $3 \mathrm{~h}$ and $16 \mathrm{~h}$ illumination at $\sim 415 \mathrm{~nm}$ (AcLO_t3 and AcLO_t16). Dotted lines represent the Gaussian components of the simulated OAS spectra. EPR spectra of complexes with $\mathrm{S}=1 / 2$ are shown in insert of $\mathrm{A}$ ) and $\mathrm{B}$ ). Optical images of films before (t0) and after illumination during $3 \mathrm{~h}(\mathrm{t} 3)$ are shown in $\mathrm{D})$.

Table S1: EPR parameters of bimetallic $\mathrm{Cu}^{\mathrm{II}}-\mathrm{Cu}^{\mathrm{II}}$ complexes before and after near-UV illumination. Hyperfine parameters A are given in $10^{-4} \mathrm{~cm}^{-1}$ and ZFS parameter D in $\mathrm{cm}^{-1}$.

\begin{tabular}{lccccc|ccc}
\hline & Ac & AcBLO t0 & $\begin{array}{r}\text { Cu-acetate } \\
\text { AcBLO t16 }\end{array}$ & AcLO t0 & AcLO t16 & Res & \multicolumn{3}{c}{ Cu-Resinate } \\
& ResBLO t0 & ResBLO t16 \\
\hline $\mathrm{g} / /$ & 2.37 & 2.38 & 2.38 & 2.38 & 2.38 & 2.37 & 2.4 & 2.4 \\
$\mathrm{~g} \perp$ & 2.07 & 2.07 & 2.07 & 2.06 & 2.06 & 2.06 & 2.07 & 2.065 \\
$\mathrm{~A} / /$ & 62 & 62 & 62 & 62 & 62 & 62 & 62 & 62 \\
$\mathrm{~A} \perp$ & 5 & 5 & 5 & 5 & 5 & 5 & 5 & 5 \\
$\mathrm{D}$ & 0.345 & 0.345 & 0.345 & 0.345 & 0.345 & 0.345 & 0.35 & 0.35 \\
$\mathrm{E} / \mathrm{D}$ & 0.03 & 0.00 & 0.00 & 0.00 & 0.00 & 0.00 & 0.00 & 0.00 \\
$\Delta \mathrm{B}$ & 20 & 10 & 10 & 35 & 15 & 10 & 5 & 5 \\
\hline
\end{tabular}


3. EPR spectra and parameters of $\mathrm{Cu} u^{\mathrm{II}}$ complexes with $\mathrm{S}=1 / 2$.

Table S2: EPR parameters used for the simulations of $\mathrm{Cu}^{\mathrm{II}}$ complexes with $\mathrm{S}=1 / 2$. Linewidth $\Delta B$ and hyperfine parameters $A_{x}, A_{y}$ and $A_{z}$ are in $\mathrm{mT}$.

\begin{tabular}{|c|c|c|c|c|c|c|c|c|c|}
\hline Compound & & & $\begin{array}{c}\text { ResBL } \\
\text { O } \\
\text { t0 }\end{array}$ & $\operatorname{Res}$ & $\begin{array}{l}\text { LO } \\
5\end{array}$ & $\begin{array}{c}\text { AcBLO } \\
\text { t0 }\end{array}$ & $\begin{array}{c}\text { AcBLO } \\
\text { t16 }\end{array}$ & $\begin{array}{c}\text { AcLO } \\
\text { t0 }\end{array}$ & $\begin{array}{c}\text { AcLO } \\
\text { t16 }\end{array}$ \\
\hline Complex & (H) & $(\mathbf{A b})$ & $(\mathbf{H})$ & $(\mathbf{H})$ & (V) & $(\mathbf{H})$ & $(\mathbf{H})$ & $(\mathbf{H})$ & $(\mathbf{H})$ \\
\hline$g_{x}( \pm 0.002)$ & 2.047 & 2.05 & 2.05 & 2.047 & 2.046 & 2.05 & 2.055 & 2.05 & 2.048 \\
\hline$g_{y}( \pm 0.002)$ & 2.069 & 2.05 & 2.069 & 2.069 & 2.046 & 2.065 & 2.063 & 2.069 & 2.065 \\
\hline$g_{z}( \pm 0.01)$ & 2.299 & 2.325 & 2.299 & 2.299 & 2.325 & 2.295 & 2.31 & 2.299 & 2.31 \\
\hline$A_{x}( \pm 0.1)$ & 1.7 & 0.5 & 1.7 & 1.7 & 0.5 & 1.7 & 1.7 & 1.7 & 1.7 \\
\hline$A_{y}( \pm 0.1)$ & 1.0 & 0.5 & 1.0 & 0.7 & 0.5 & 1.0 & 0.5 & 1.0 & 0.5 \\
\hline$A_{z}( \pm 0.5)$ & 16.0 & 13.4 & 15.2 & 16.0 & 13.4 & 15.2 & 13.9 & 15.2 & 13.9 \\
\hline$\Delta B( \pm 0.01)$ & 0.8 & 0.8 & 1.7 & 0.8 & 0.8 & 1.7 & 1.7 & 1.7 & 1.7 \\
\hline$g$-strain $x, y$ & 0.005 & 0.005 & 0.005 & 0.005 & 0.005 & 0.005 & 0.005 & 0.005 & 0.005 \\
\hline$g$-strain $z$ & 0.03 & 0.03 & 0.05 & 0.03 & 0.03 & 0.05 & 0.05 & 0.05 & 0.05 \\
\hline $\begin{array}{l}A \text {-strain } x, y \\
(\mathrm{mT})\end{array}$ & 0.3 & 1.0 & 0.3 & 0.3 & 1.0 & 0.3 & 0.5 & 0.5 & 0.5 \\
\hline $\begin{array}{l}A \text {-strain } z \\
(\mathrm{mT})\end{array}$ & 2.0 & 2.0 & 2.0 & 2.0 & 2.0 & 1.0 & 1.0 & 1.0 & 1.0 \\
\hline
\end{tabular}
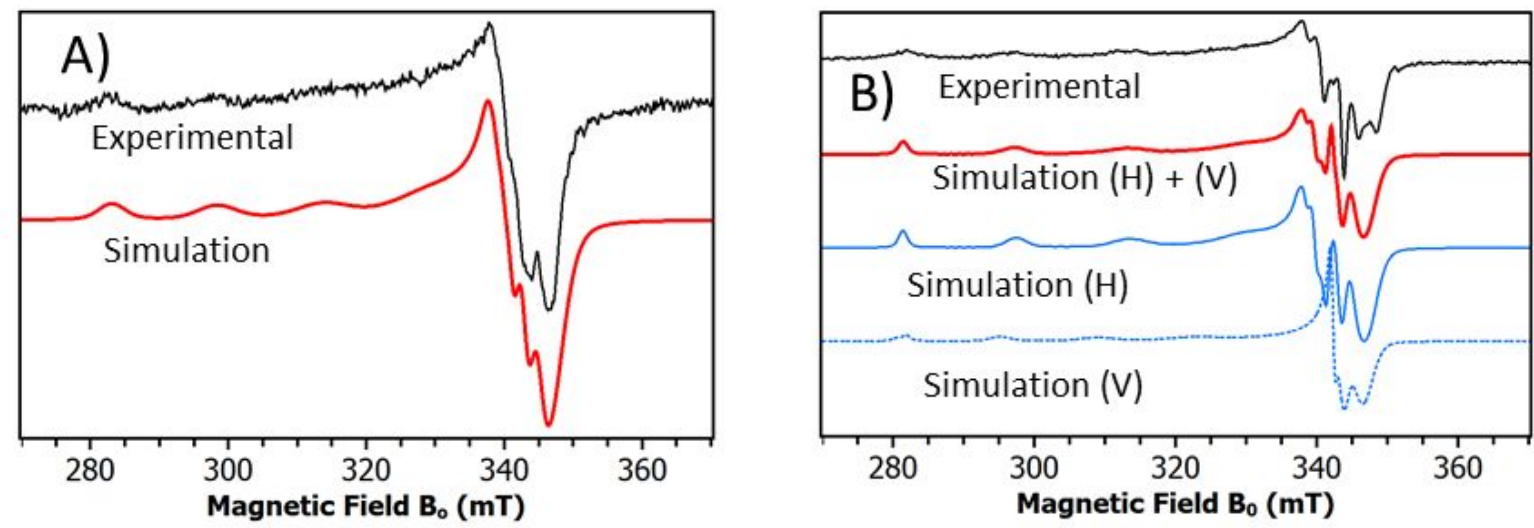

Figure S3. Experimental and simulated EPR spent at X-band of A) «monomer» $(\mathrm{H})$ in dry ResBLO film, and $B)$ the sum of monomers $(\mathrm{H})$ and $(\mathrm{V})$ in ResBLO film illuminated at $\sim 24000 \mathrm{~cm}^{-1}(410-420 \mathrm{~nm})$ with a LED during $16 \mathrm{~h}$. 
4. Proportions of $\mathrm{Cu}^{\mathrm{II}}$ dimers $(\mathrm{S}=1)$ and monomers $(\mathrm{S}=1 / 2)$ in pigment-oil films.

Table S3 : Proportion of dimers $(\mathrm{S}=1)$ and monomers $(\mathrm{S}=1 / 2)$ deduced from EPR measurements before $(\mathrm{t} 0)$ and after illumination at $\sim 24000 \mathrm{~cm}^{-1}(410-420 \mathrm{~nm})$ with a LED during $16 \mathrm{~h}$

\begin{tabular}{lcccccc}
\hline & AcLO_t0 & AcLO_t16 & AcBLO_t0 & AcBLO_t16 & ResBLO_t0 & ResBLO_t16 \\
\hline Cu total (\%) & 100 & 60 & 100 & 96 & 100 & 82 \\
$\mathrm{~S}=1 / 2(\%)$ & $14 \pm 4$ & $9 \pm 7$ & $41 \pm 4$ & $17 \pm 7$ & $31 \pm 6$ & $46 \pm 16$ \\
$\mathrm{~S}=1(\%)$ & $86 \pm 4$ & $51 \pm 14$ & $59 \pm 4$ & $79 \pm 10$ & $69 \pm 6$ & $36 \pm 6$
\end{tabular}

5. Effect of near-UV illumination on optical absorption of linseed oil

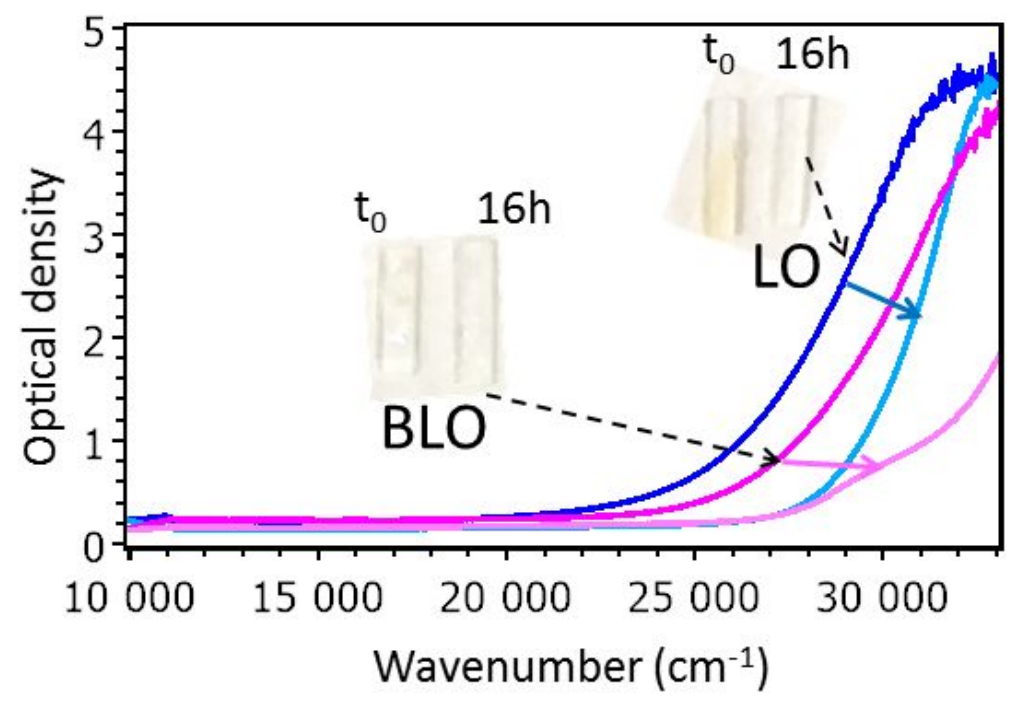

Figure S4. Optical absorption of raw linseed oil (LO) and boiled linseed oil (BLO) before (t0) and after illumination at $\sim 24000 \mathrm{~cm}^{-1}(410-420 \mathrm{~nm})$ with a LED during $16 \mathrm{~h}$. The show the optical images of linseed oil films. LO is slightly yellow, and becomes transparent after illumination. 